\section{REFERENCES}

Andrews, P., Hough, L. \& Jones, J. K. N. (1952). J. Amer. chem. Soc. 74, 4029.

Bell, D. J. \& Palmer, A. (1952). J. chem. Soc. p. 3763.

Bertrand, F. \& Laszt, L. (1956). Biochem. Z. 327, 354.

Consden, R. \& Stanier, W. M. (1952). Nature, Lond., 169, 783.

Dedonder, R. (1952). Bull. Soc. chim. Fr. 34, 144.

Devor, A. W. (1950). J. Amer. chem. Soc. 72, 2008.

Dorée, C. (1947). The Methods of Cellulose Chemistry, 2nd ed., p. 425. London: Chapman and Hall, Ltd.

Foster, A. B. (1953). J. chem. Soc. p. 982.

Foster, A. B., Newton-Hearn, P. A. \& Stacey, M. (1956). J. chem. Soc. p. 30.
Geldmacher-Mallinckrodt, M. \& Wienland, H. (1953). Hoppe-Seyl. Z. 292, 65.

Greenway, R. M., Kent, P. W. \& Whitehouse, M. W. (1953). Research, Lond., 6, suppl. 1, 65.

Hough, L., Jones, J. K. N. \& Wadman, W. H. (1950). J. chem. Soc. p. 1703.

Huffman, G. W., Rebers, P. A., Spriestersbach, D. R. \& Smith, F. (1955). Nature, Lond., 175, 990.

May, F. (1934). Z. biol. 95, 277.

Nelson, N. (1944). J. biol. Chem. 153, 375.

Northcote, D. H. (1953). Biochim. biophys. Acta, 11, 471.

Northcote, D. H. (1954). Biochem. J. 58, 353.

Preece, I. A. \& Hobkirk, R. (1955). Chem. \& Ind. p. 257.

Rienits, K. G. (1953). Biochem. J. 53, 79.

\title{
Helicorubin and Gytochrome $h$
}

\author{
PURIFICATION AND PHYSICAL PROPERTIES
}

\author{
BY JOAN KEILIN* \\ Department of Biochemistry and Molteno Institute, University of Cambridge
}

(Received 25 January 1956)

Helicorubin is a naturally occurring haemochromogen found in the crop and intestinal tract of land snails and some other invertebrates. It is the only known extracellular haemoprotein apart from haemoglobin and chlorocruorin, and in many of its properties it resembles some of the components of cytochrome. Although helicorubin was the first haemoprotein of the haemochromogen type to be described, it was never purified, and all the properties so far attributed to it have been those of the crude material.

In 1876 Sorby found that the crop and intestine of the garden snail contain a red-brown fluid which has an absorption spectrum very like that of a haemochromogen; he also found that this type of absorption spectrum could be seen in the digestive gland ('liver' or hepatopancreas) and other organs. When exposed to air, the pigment underwent oxidation and its strong absorption bands disappeared, but they reappeared when the fluid was made alkaline and the pigment became reduced. Sorby's observations were confirmed by Krukenberg (1882), who named the pigment 'helicorubin', and by MacMunn (1883, 1885, 1886a,b), who named it 'enterohaematin'. The name 'helicorubin' given by Krukenberg has now been generally adopted.

The first attempt at the purification of helicorubin was made by Dhéré \& Vegezzi $(1917 a, b)$ and Dhéré (1919), who ultrafiltered snail 'bile' and

* Present address: Department of Veterinary Clinical Studies, School of Veterinary Medicine, University of Cambridge. separated a red solution containing helicorubin, which passed through the collodion membrane, from a brown pigment which they named 'helicofuscine'. They found that alkaline helicorubin has a haemochromogen type of absorption spectrum consisting of a sharp $\alpha$-band at $562.5 \mathrm{~m} \mu$, a weaker $\beta$-band at $529.5 \mathrm{~m} \mu$., and a $\gamma$-(Soret) band at $427.5 \mathrm{~m} \mu$. The absorption bands in the visible region can be seen when snail 'bile' is examined in situ by transilluminating a loop of the intestine, and their positions agree with those recorded by Sorby (1876).

On acidification of the 'bile', these sharp bands are replaced in the visible region of the spectrum by the two diffuse bands of oxidized helicorubin; of these the $\beta$-band is stronger than the $\alpha$-band, and the $\gamma$-band now lies at $415 \mathrm{~m} \mu$. The oxidized, acid helicorubin may be changed to reduced helicorubin either by the addition of alkali or by treating the acid solution with a reducing agent, e.g. sodium dithionite. In the latter case the $\alpha$-band of the haemochromogen is asymmetrical near its peak, and on direct spectroscopic examination appears to be double. Dhéré \& Vegezzi concluded that helicorubin is a protein with the same prosthetic group as haemoglobin.

Anson \& Mirsky (1925) claimed, from work with crudesnail 'bile', that helicorubin is a haemochromogen capable of undergoing oxygenation as well as oxidation, but this claim has not been confirmed.

Roche \& Morena $(1936 a, b)$, using material which had been partly cleared of other pigments 
either by passing snail 'bile' through calcium carbonate or by filtration, studied the variation of the degree of reduction with $\mathrm{pH}$ of the pigment and found that $50 \%$ reduction occurred at about $\mathrm{pH} \mathbf{7 \cdot 3}$. They suggested that the reducing action of alkali may be due to the dissociation of either a reducing substance co-existing with the pigment in the comparatively crude preparation (as had been suggested by Dhéré \& Vegezzi, $1917 b$ ) or of an active reducing group from the helicorubin protein itself.

Since helicorubin from the gastro-intestinal tract and the haemochromogen from the digestive gland have now been greatly purified and shown to differ from each other in certain respects, the term helicorubin will be used only for the haemochromogen found free in the gastro-intestinal fluid. Although the intracellular haemochromogen from the digestive gland resembles cytochromes $b$ and $c$, yet in several of its properties it differs from them and from all the cytochrome components which have been recorded so far. It is therefore proposed to describe it here under the name of cytochrome $h$, thus indicating its close connexion with helicorubin, which is probably derived from it and represents its extracellular form, liberated and somewhat modified during the course of the normal glandular secretion of the digestive gland. The nomenclature of the terms helicorubin and cytochrome $h$ may ultimately have to be revised as more properties of the $b$ and $c$ groups of cytochrome become known.

This paper describes the isolation and purification of helicorubin from the gastro-intestinal fluid and of cytochrome $h$ from the digestive gland (hepatopancreas) of the snail Helix pomatia. This is followed by an account of the physical properties of these pigments; their biological properties as compared with those of the well-known components of cytochrome will be dealt with in a later paper.

\section{MATERIALS AND METHODS}

Source of material. Both haemoproteins helicorubin and cytochrome $h$ were obtained from the edible 'Roman' snail, H. pomatia.

pH values of solutions. These were determined with a micro glass electrode (Hartree, 1952) used in conjunction with a Pye universal $\mathrm{pH}$ meter.

Filtrations. These were carried out through a layer of 'Celite Hyflo' supported on a no. 3 porosity sintered-glass funnel.

Electrophoretic fractionation on paper. The method of Consden \& Stanier (1952) was adopted by using a thick paper (Whatman no. $3 \mathrm{MM}$ ) immersed in $\mathrm{CCl}_{4}$ (A.R.) or chlorobenzene as heat-dispersant. To reduce changes in $\mathrm{pH}$ which were found to occur in phosphate buffer over a period of $24 \mathrm{hr}$., deep Perspex electrode vessels were used, each of 21 . capacity, containing $0.066 \mathrm{M}$ phosphate buffer and fitted with $\mathrm{Pt}$ wire electrodes.

The purified helicorubin (see p. 666) was freeze-dried, and 30-50 mg., according to the width of the paper, was dis- solved in a minimal amount of the buffer and applied with a capillary pipette to the paper strip in the usual way. With paper strips between 10 and $22 \mathrm{~cm}$. in width and an average potential gradient of $6 \mathrm{v} / \mathrm{cm}$. the current varied between $1 \cdot 0$ and $1.6 \mathrm{~mA} / \mathrm{cm}$. width of the paper over a period of $22 \mathrm{hr}$. When it was required to record the results of the electrophoresis, the strip was gently dried in a current of warm air and photographed in short-wave ultraviolet light as described by Markham \& Smith (1951). An exposure of 3-5 min. was given and Kodak reflex document paper was used. The coloured bands were then cut out of the strip and the pigment of each band was eluted with water by capillarity.

Moving-boundary electrophoresis. A Perkin Elmer model of the Tiselius apparatus was used with a cell of $2 \mathrm{ml}$. capacity. By the use of the tungsten light source of the apparatus and Ilford HP3 photographic plates a very satisfactory negative was obtained in which the red limb of the boundary usually appeared slightly grey. An alternative arrangement which gave a completely black negative picture was the substitution of the diffusing screen in front of the light source by a red filter (Ilford no. 608). The electrophoretic mobility was determined at $1^{\circ}$ and expressed in $\mathrm{cm}^{2} \mathrm{v}^{-1}$ sec. $^{-1}$.

Sedimentation coefficient. All determinations were made in the Spinco analytical ultracentrifuge. The rotor speed was $59780 \mathrm{rev} . / \mathrm{min}$. unless otherwise stated, and photographs were taken every $16 \mathrm{~min}$. The haemoprotein was prepared by dialysis for about $24 \mathrm{hr}$. against $0.1 \mathrm{~m}$ phosphate buffer.

Diffusion coefficient. This was measured in the Tiselius apparatus described above. The boundary was displaced by means of a glass plunger slowly lowered by a clockwork mechanism into the left electrode vessel and was then sharpened by the method described by Kahn \& Polson (1947). Photographs were taken at $\frac{1}{2} \mathrm{hr}$. intervals for $7 \frac{1}{2} \mathrm{hr}$. with a red filter (Ilford no. 608) in place of the diffusing screen and HP3 plates as described for moving-boundary electrophoresis, the average temperature being $18 \cdot 5^{\circ}$.

Spectroscopic methods. For direct spectroscopic observations of the pigments a low-dispersion microspectroscope was used.

The absorption spectra in the visible and ultraviolet regions were determined with a Beckman photoelectric spectrophotometer or by two Hilger Uvispek spectrophotometers fitted with glass and quartz prisms respectively, so as to obtain the maximum degree of dispersion over the whole range of the spectrum. Glass or silica cells of 0.5 and $1.0 \mathrm{~cm}$. light-path were used. The molecular absorption coefficient $\epsilon$ is defined as $E / c l$, where $c$ represents the molarity of the helicorubin solution in terms of its haematin Fe content, $l$ the optical light path in $\mathrm{cm}$. and $E$ (extinction) is $\log I_{0} / I$, where $I_{0}$ and $I$ are the intensities of the incident and transmitted light respectively.

Dry weight. Purified helicorubin which had been dialysed against water till salt-free was freeze-dried, transferred to a weighing bottle and kept in a desiccator over $\mathrm{P}_{2} \mathrm{O}_{5}$ before being weighed as rapidly as possible, since the material tends to absorb atmospheric moisture. Standard solutions of the helicorubin in water were prepared and used for the subsequent estimations of $\mathrm{Fe}$, protein $\mathrm{N}$ and carbohydrate.

Iron. The haematin $\mathrm{Fe}$ is liberated by the action of $\mathrm{H}_{2} \mathrm{O}_{2}$ in alkaline solution (Hill \& Keilin, 1933) and estimated colorimetrically as the $\mathrm{Fe}-\alpha \alpha^{\prime}$-dipyridyl complex as described by Keilin \& Hartree (1945). 
Protein nitrogen. This was estimated by the microKjeldahl method (Markham, 1942); the $\mathrm{NH}_{3}$ was collected in boric acid reagent (Abelin, 1938) and titrated with standardized $\mathrm{HCl}$. It was assumed that the protein content was $6 \cdot 25$ times the $\mathrm{N}$ content of the sample.

Carbohydrate. The Molisch reaction was used to detect the presence of carbohydrate. For quantitative determinations Devor's modification (1950) of the Molisch reaction was used.

\section{EXPERIMENTAL AND RESULTS}

\section{Purification of helicorubin and of cytochrome $\mathrm{h}$}

Collection of material. The best source of material was found to be the edible or 'Roman' snails, $H$. pomatia, which are imported into this country from France during the winter months while they are in a state of starvation and hibernation. They can therefore be kept at $4^{\circ}$ for any length of time until required. The garden snail, $H$. aspersa, was also used as a source of helicorubin, but was found to be less practical on account of its smaller size and the necessity to starve it.

For each preparation of helicorubin or cytochrome $h$, about 200 snails $(H$. pomatia) are used. The shells are cracked in a mortar and carefully removed. When the snail is uncoiled, the intestine appears on the inner surface as a bright-red loop in which can be seen, on direct spectroscopic examination, the strong haemochromogen-like absorption bands of reduced helicorubin. The intestine is gently pulled away from the snail, bringing with it the large 'crop' and exposing the junction of the intestinal tract with the digestive gland (hepatopancreas). The intestine is torn away from the digestive gland and the entire contents of the gastro-intestinal tract are drained into a beaker, where the red fluid gradually darkens to a red-brown colour. As much as possible of the gastro-intestinal tract is removed, together with the digestive gland, which is a dark-brown friable organ occupying the terminal spirals of the shell. These tissues are washed with water and stored at $-16^{\circ}$ until required. The washings may be added to the gastrointestinal contents or worked up separately.

The gastro-intestinal fluid collected as described above contains a number of substances which make purification of helicorubin difficult, especially in the early stages. The fluid is heavily contaminated by mucin, which makes it very viscous, and by haemocyanin, the copper-protein oxygen carrier which is liberated during the rapid but crude dissection of the snail. The fluid is also rich in brown and yellow pigments which tend to mask the absorption spectrum of helicorubin, particularly in the green, blue and violet regions of the spectrum. Finally the presence of a powerful cellulase precludes the use of any method depending on dialysis through cellophan tubing or filtration through paper until the enzyme has been inactivated. However, by taking advantage of the fact that helicorubin and cytochrome $h$ are thermostable proteins, the cellulase can easily be irreversibly inactivated by warming the pigment-containing extracts to $68^{\circ}$ for about $30 \mathrm{~min}$.

Assessment of degree of purification. The oxidized form of helicorubin has a parahaematin type of absorption spectrum with a broad absorption band in the green region of the spectrum and a very sharp $\gamma$-(Soret) band in the violet region. The deepening of the trough between the absorption bands and the resulting sharpening of the bands denotes the removal of coloured impurities. The characteristic absorption curves ( $\log E$ plotted against wavelength), which are independent of the concentration of the pigment under investigation, permit accurate comparisons of different solutions to be made. For rapid comparisons, however, it is convenient to measure the ratios of the peaks of the main bands to the adjacent troughs. As purification proceeds, the most significant change is the reduction in height of the protein band at $276 \mathrm{~m} \mu$. relative to the Soret band, i.e. the $E$ (protein) $/ E$ (Soret) ratio $\left(E_{\mathrm{p}} / E_{\mathrm{g}}\right)$. At each stage the positions and shapes of all the absorption bands of the reduced pigment were also noted.

Other criteria used for the assessment of purification were the $\mathrm{Fe} /$ protein ratio and the electrophoretic behaviour of the pigment.

\section{Purification of helicorubin}

About $100 \mathrm{ml}$. of diluted gastro-intestinal fluid from 200 snails is filtered through glass wool and further diluted with water to about $350 \mathrm{ml}$., giving an opalescent, brown, sticky and slightly acid solution ( $\mathrm{pH}$ 6.0).

Lead acetate precipitation of impurities (I). Sufficient basic lead acetate (about $50 \mathrm{ml}$. of $25 \%, \mathrm{w} / \mathrm{w}$ ) is added to the solution made alkaline with $10 \%(\mathrm{v} / \mathrm{v})$ aqueous $\mathrm{NH}_{3}$ (sp.gr. $\mathbf{0 . 8 8 0}$ ) to produce maximum precipitation. The heavy greenish brown, curd-like precipitate is removed by centrifuging for 30-40 min. at $2000 \mathrm{rev}$./min. (In some cases the precipitate is so heavy that it is necessary to dilute the preparation with water before centrifuging.) The precipitate is washed twice by centrifuging with alkaline water $(\mathrm{pH}$ 8-9) containing about $5 \mathrm{ml}$. of basic lead acetate solution/ $100 \mathrm{ml}$. of $\mathrm{H}_{2} \mathrm{O}$ and the washings are added to the supernatant. The solution is filtered through a bed of kieselguhr (Celite Hyflo) on a sintered-glass filter. The clear red solution thus obtained tends on standing to form a fine white precipitate which is probably a mixture of lead carbonate and hydroxide, but this is disregarded. The solution is brought to $\mathrm{pH} 6$ with acetic acid and excess of lead is precipitated by adding a saturated solution of $\mathrm{Na}_{8} \mathrm{SO}_{4}$ and removed by centrifuging, leaving about $1100 \mathrm{ml}$. of clear red solution.

Concentration of the pigment and fractionation with ammonium sulphate (II). The solution is now brought to pH 7.3 with $10 \%(v / v)$ aqueous $\mathrm{NH}_{3}$ (sp.gr. 0.880), treated with $430 \mathrm{~g}$. $/$ l. of $\left(\mathrm{NH}_{4}\right)_{2} \mathrm{SO}_{4}$ to bring it to approximately $65 \%$ saturation (discounting the $\mathrm{Na}_{2} \mathrm{SO}_{4}$ previously added) and left at $0^{\circ}$ overnight. The helicorubin, which is precipitated, is filtered off on a bed of Celite Hyflo and the lemon-yellow filtrate is discarded. The precipitate is washed on the filter with neutralized $65 \%$ saturated $\left(\mathrm{NH}_{4}\right)_{2} \mathrm{SO}_{4}$ until the washings are colourless; the precipitate and kieselguhr are then removed from the funnel and slurried with water; the dissolved pigment is filtered off and the kieselguhr is washed with successive small quantities of water till it is colourless. The dark-red solution is now dialysed in a cellophan tube against $65 \%$ saturated $\left(\mathrm{NH}_{4}\right)_{2} \mathrm{SO}_{4}$ overnight, the cellulase being reversibly inactivated by the $\left(\mathrm{NH}_{4}\right)_{2} \mathrm{SO}_{4}$. The precipitated helicorubin is filtered off and washed with neutralized $\left(\mathrm{NH}_{4}\right)_{2} \mathrm{SO}_{4}$ as described above. The brightyellow filtrate and the washings are discarded. The precipitated pigment is now washed through the filter with the minimum amount of water and dialysed against several changes of tap water in a vessel of about 61 . capacity for 8-12 hr. The cellophan tubes must then be handled very 
carefully as they are frequently much weakened by the reactivated cellulase and are liable to develop small leaks. As much as possible of the $\left(\mathrm{NH}_{4}\right)_{2} \mathrm{SO}_{4}$ must be removed in this way since the presence of the salt tends to prevent the destruction of the cellulase in the next stage.

Heat inactivation of cellulase (III). Karrer, Schubert \& Wehrli (1925) found that Helix pomatia cellulase is inactivated by heating at $60^{\circ}$ for $1 \mathrm{hr}$. at $\mathrm{pH} 5 \cdot 28$. Such treatment does not cause any denaturation of helicorubin or of cytochrome $h$, since both these haemoproteins retained their characteristic properties of non-reactivity with carbon monoxide, very slow autoxidation in the physiological range of pHand oxido-reduction reactions with biological systems.

By taking advantage of the thermostability of the haemoprotein, the solution, about $300 \mathrm{ml}$, is adjusted to $\mathrm{pH} 6$ with $\mathrm{M}$ acetic acid and heated on a water bath to $68^{\circ}$ for $30 \mathrm{~min}$.; if the salt concentration of the solution is sufficiently low this treatment completely destroys the cellulase activity. A grey precipitate appears at $50^{\circ}$ and soon forms a heavy flocculum. After cooling, the precipitate is centrifuged off and washed twice with water; the supernatant and washings are mixed, brought to $\mathrm{pH} 8$ with $10 \%(\mathrm{v} / \mathrm{v}) \mathrm{NH}_{3}$ solution (sp.gr. 0.880 ) and clarified by centrifuging, about $20 \mathrm{ml}$. of tricalcium phosphate gel being added if necessary. The clear helicorubin solution (320 ml.) can now be dialysed against several changes of water and concentrated by suspending the dialysis tubes in front of an electric fan. Any precipitate formed during these procedures is removed by centrifuging. When the solution is salt-free and has been reduced to about $20 \mathrm{ml}$. it is freeze-dried in readiness for electrophoretic fractionation on paper.

\section{Preparation of cytochrome $\mathrm{h}$ from the digestive gland}

The digestive glands (of about 200 snails) which had been stored at $-16^{\circ}$ are slightly warmed and while still partly frozen are blended with a little water in a Waring Blendor for $1 \mathrm{~min}$. The thick fluid is centrifuged, the supernatant collected and the precipitate washed once with water by centrifuging; the washings are added to the supernatant. Care is taken during all these procedures to keep the fluid at about $\mathrm{pH} 7$, since in some preparations there is a tendency for it to become very acid. About 1 l. of opaque brown fluid is obtained, which is then treated with lead acetate followed by the steps of purification described above for helicorubin, yielding material suitable for fractionation by electrophoresis on paper.

\section{Electrophoretic fractionation of helicorubin and cytochrome h (IV)}

Each preparation was subjected to electrophoretic fractionation on paper as described, with $0.066 \mathrm{M}$ phosphate buffer between pH 6.5 and 7.5. In each case the direction of migration of the haemoprotein relative to uncharged markers such as glucose or adenine was towards the positive electrode.

Fractionation of cytochrome $h$ preparations (Fig. 1) which usually had an $E_{\mathrm{p}} / E_{\mathrm{s}}$ ratio of between 0.5 and 1.0 gave rise to one red band (cytochrome $h$ ) which was the slowest-moving component and was well separated from a broad cream-coloured zone $(P)$. A photograph of the paper strips in ultraviolet light defines the extent of the slightly coloured and uncoloured protein bands $P, P^{\prime}$ and $P^{\prime \prime}$.

Spectrophotometric examination of the coloured components after their elution from the paper showed that the red band contained $\mathbf{7 7} \%$ of the total pigment, but only $35-40 \%$ of the total protein. The $E_{\mathrm{p}} / E_{\mathrm{s}}$ ratio of the cytochrome $h$ component (oxidized) was now between 0.28 and $0 \cdot 31$, that of fraction $P$ was $0 \cdot 5-2 \cdot 0$ and that of fraction $P^{\prime}$ was as high as $6 \cdot 7$. The Soret band of cytochrome $h$ lay at $410 \mathrm{~m} \mu$., and that of fractions $P$ and $P^{\prime}$ was at $412-414 \mathrm{~m} \mu$.

Helicorubin preparations gave a more complex picture on paper electrophoresis (Fig. 2). In many cases two red bands appeared; the positions of the Soret absorption bands of the eluted pigments showed that the slowest-moving component was cytochrome $h$ (present only in small amounts, if at all) while the main red band was that of helicorubin. (The spectroscopic differences between these two pigments are discussed below.) Cytochrome $h$ appeared in all preparations where the washings of the cut-up digestive gland had been worked up with the gastro-intestinal fluid and was probably contained in these washings. In preparations of helicorubin which did not appear to contain cytochrome $h$ when electrophoresis was carried out in phosphate or in acetate buffers between $\mathrm{pH} 5.5$ and $7 \cdot 5$, a cytochrome $h$ component did appear on electrophoresis at $\mathrm{pH} 4$ or below. This suggests that under certain conditions helicorubin may in some way be changed to cytochrome $h$. This point, which may throw light on the exact relationship between cytochrome $h$ and helicorubin, requires further study. Two or three other faintly coloured bands, $p, p^{\prime}$ and $p^{\prime \prime}$, are usually seen on the paper strip, and eluates of these bands contain progressively less haematin relative to their protein content. In each case the position of the Soret band of these haemoproteins was

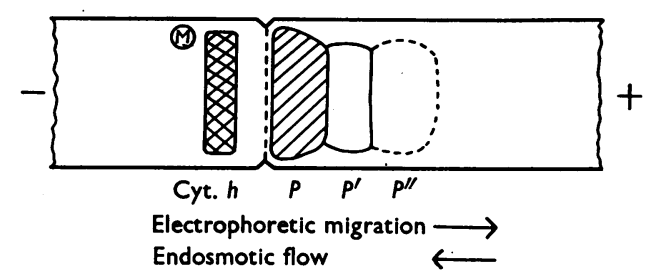

Fig. 1. Diagram of electrophoretic fractionation on paper of cytochrome $h$, showing typical positions of cytochrome $h$ and other proteins $\left(P, P^{\prime}\right.$ and $\left.P^{\prime \prime}\right)$ relative to an uncharged marker $M$ (adenine) after $22 \mathrm{hr}$. electrophoresis in $0.066 \mathrm{M}$ phosphate buffer, $\mathrm{pH} \mathrm{7.4}$. The material was applied to the paper in the position of the broken line. The positions of the uncoloured proteins and adenine are revealed by photographing the paper strip in u.v. light as described.

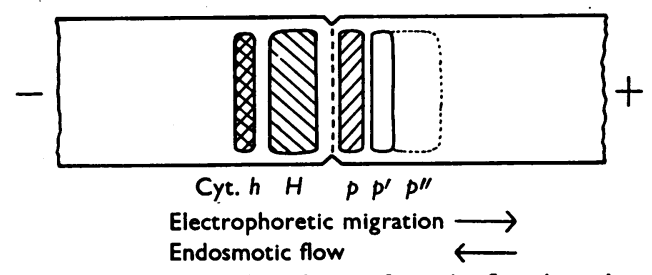

Fig. 2. Diagram of the electrophoretic fractionation on paper of helicorubin $(H)$ showing its separation and that of a small amount of cytochrome $h$ from other protein material $p, p^{\prime}$ and $p^{\prime \prime}$ after $22 \mathrm{hr}$. electrophoresis in $0.066 \mathrm{M}$ phosphate buffer, pH $7 \cdot 4$ (see Fig. 1). 
the same as that of the helicorubin (414-415 $\mathrm{m} \mu$.). It therefore appears that helicorubin, and to some extent also cytochrome $h$, tend to be attached to several other proteins. This 'attached' haemoprotein accounts for about $23 \%$ of the pigments and it explains why helicorubin and cytochrome $h$ are precipitated by ammonium sulphate over the whole range between 40 and $60 \%$ saturation so that fractionation with ammonium sulphate cannot be used in the purification of cytochrome $h$ and helicorubin.

The different fractions obtained on electrophoresis were dialysed against water till salt-free, and were either freezedried or stored at $-16^{\circ}$. It was found that towards the end of this dialysis concentrated solutions of helicorubin and cytochrome $h$ tended to become adsorbed on the cellophan tubing in the same way as cytochrome $c$.

The progress of the purification of a typical preparation of helicorubin as described above is shown in Fig. 3. The spectrophotometric criteria selected (for the oxidized form of the pigment) were: (a) the increase in the extinction of the Soret band relative to the extinction of the trough at $500 \mathrm{~m} \mu$., which shows the progressive elimination of the brown and

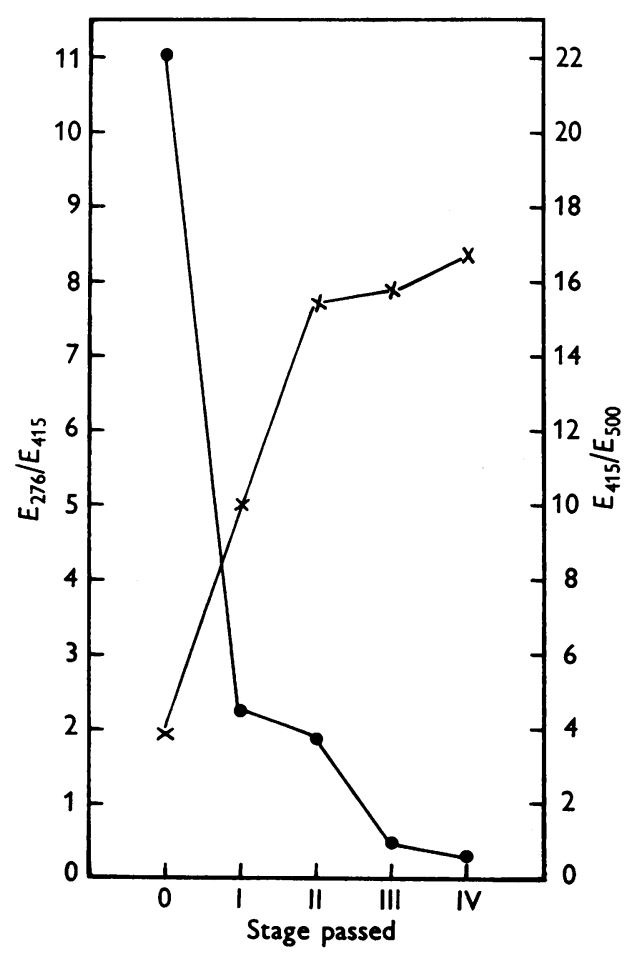

Fig. 3. Spectrophotometric evaluation of the progress of purification of helicorubin. The criteria used are the ratios of the extinction of the protein band to that of the Soret band $\left(E_{276 \mathrm{~m} \mu .} / E_{415 \mathrm{~m} \mu}\right)$ and the ratio of the extinction of the Soret band to that of the trough adjacent to it $\left(E_{415 \mathrm{~m} \mu .} / E_{508 \mathrm{~m} \mu .}\right)$. Very similar results are obtained in the purification of cytochrome $h$, but owing to the solid nature of the starting material no values can be obtained for the initial condition of the pigment. $x$, $E_{415 \mathrm{~m} \mu .} / E_{500 \mathrm{~m} \mu .} ; E_{976 \mathrm{~m} \mu} / E_{415 \mathrm{~m} \mu .}$. The stages of the preparation are described in the text. yellow pigments and other substances absorbing over this region of the spectrum; $(b)$ the decrease in the height of the protein band relative to the height of the Soret band, which indicates the removal of non-helicorubin protein. This ratio must not be interpreted too literally in the early stages of purification, for in the relatively crude preparations $E_{\mathrm{s}}$

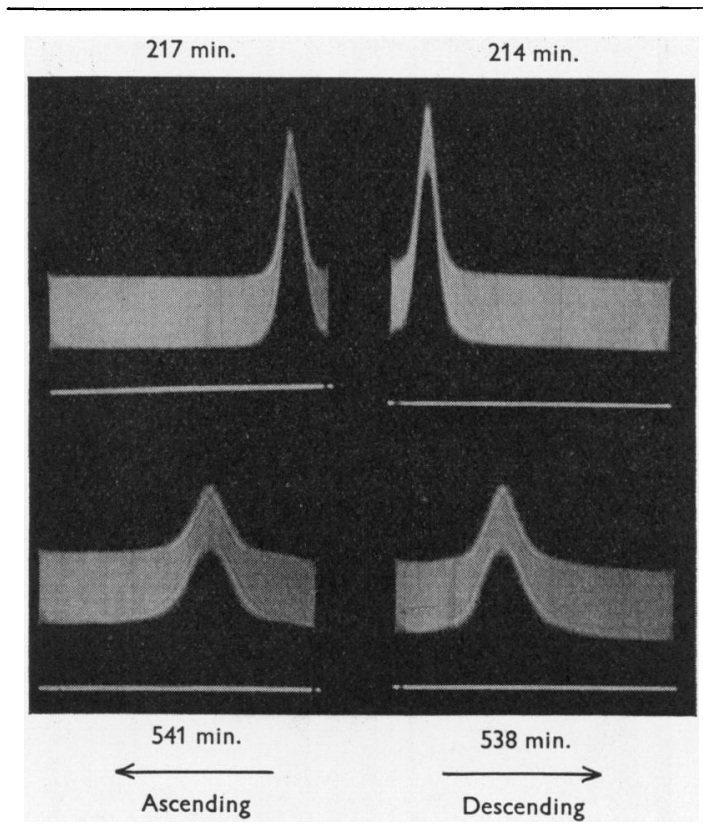

Fig. 4. Electrophoretic schlieren patterns of helicorubin at pH 6.5 in phosphate- $\mathrm{NaCl}(I 0.2) . \mu=0.706 \times 10^{-5} \mathrm{~cm} .^{2}$ sec. $^{-1} \mathrm{v}^{-1}$.

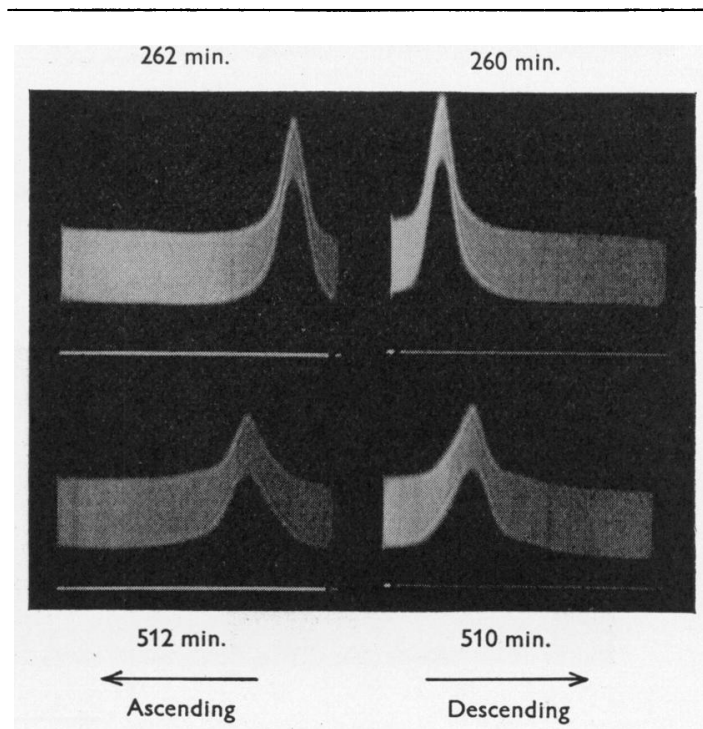

Fig. 5. Electrophoresis patterns of cytochrome $h$ at pH 6.94 in phosphate- $\mathrm{NaCl}(I, 0.2) . \mu=0.811 \times 10^{-5} \mathrm{~cm}^{2}$. sec. ${ }^{-1} \mathrm{v}^{-1}$. See also Table 1 . 
represents the absorption of the Soret band together with that of an unknown amount of absorption due to other pigments. Electrophoretic fractionation on paper, although slow and tedious, has the advantage that the total pigment can invariably be recovered in the various fractions.

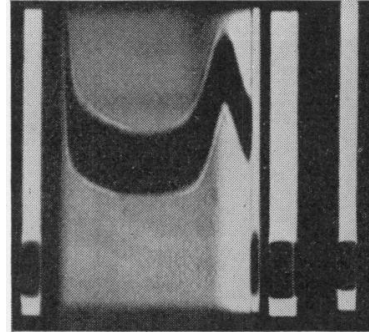

(b)

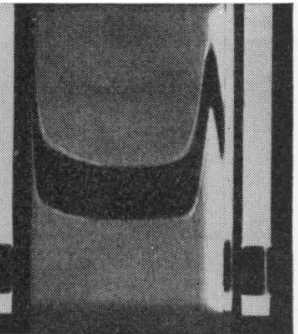

(a)
Fig. 6. Sedimentation pattern of helicorubin showing the migration of the colour boundary with the peak. $0.1 \mathrm{M}$ Phosphate buffer, pH 6•1. I 0·125. Rotor speed 59780 rev./min. Exposures at (a) 32 min., (b) $64 \mathrm{~min}$.

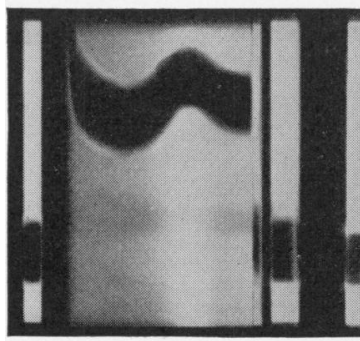

(b)

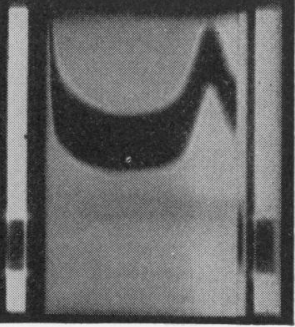

(a)
Fig. 7. Sedimentation pattern of cytochrome $h$ in $0 \cdot 1 \mathrm{~m}$ phosphate buffer, pH 7.9. I 0.26. Rotor speed 59780 rev./min. Exposures at (a) $80 \mathrm{~min}$. , (b) $176 \mathrm{~min}$. See Table 1.

\section{Examination of preparations for homogeneity}

Moving-boundary electrophoresis. The electrophoretic mobilities of helicorubin and cytochrome $h$ were examined in acetate and phosphate buffers of constant ionic strength $(I 0.2)$ between $\mathrm{pH} 4.5$ and 7.2. In all cases the haemoprotein migrated towards the anode, but the rate of migration was slow and most experiments were continued for $7-9 \frac{1}{2} \mathrm{hr}$., with solutions of approximately $0.5 \%(w / v)$ in terms of protein. Under these conditions the mobility of the haemoprotein varied from $0.36 \times 10^{-5}$ to $0.93 \times 10^{-5}$ cm. $^{2}$ sec. $^{-1} \mathrm{v}^{-1}$ at $\mathrm{pH} 4.48$ and $7 \cdot 2$ respectively. Since the haemoproteins may undergo some modification when kept at $\mathrm{pH} 4$ or below for more than a few hours, no mobility determinations were made below pH 4.48. However, the results obtained indicate that both helicorubin and cytochrome $h$ are acidic in nature and that their isoelectric points lie below pH $4 \cdot 3$.

It can be seen in Figs. 4 and 5 that the preparations of helicorubin and cytochrome $h$ examined in phosphate-NaCl buffer at $\mathrm{pH} 6.9$ and 6.5 respectively show only one symmetrical boundary.

Behaviour in the ultracentrifuge. The sedimentation patterns of these preparations in the Spinco ultracentrifuge also showed only one component in each case (Figs. 6-8). At the maximum rotor speed of $59780 \mathrm{rev} . / \mathrm{min}$., sedimentation of both helicorubin and cytochrome $h$ was slow and, as can be seen best in Fig. 6, the red colour of the haemoprotein (seen as a grey background to the boundary on the viewing screen of the centrifuge) migrated with the boundary. Since all the preparations were known to contain polysaccharide material (see below) and yet appeared to be homogeneous when sedimenting at the top speed of the centrifuge, a run was performed in which the maximum speed was approached very gradually, and a watch was kept for any indication of the presence of a very rapidly sedimenting component which might be spun down before the centrifuge had reached full speed. No evidence of any

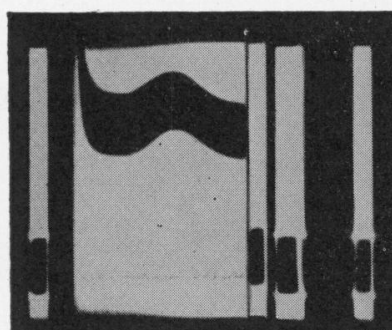

(d)

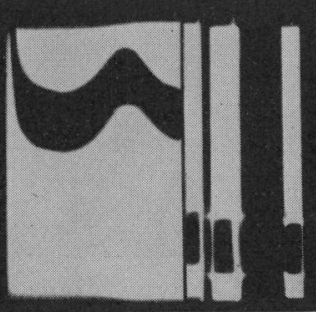

(c)

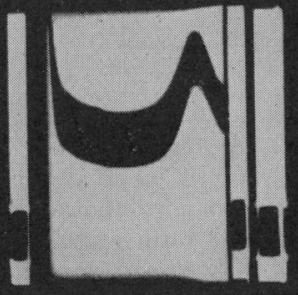

(b)

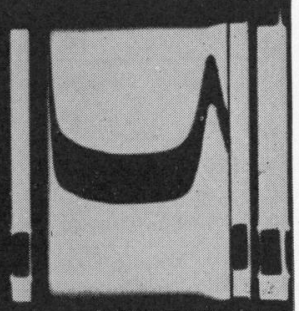

(a)

Fig. 8. Sedimentation pattern of helicorubin in $0 \cdot 1 \mathrm{~m}$ phosphate buffer, $\mathrm{pH} 6 \cdot 1$. I $0 \cdot 125$. Rotor speed $59780 \mathrm{rev} . / \mathrm{min}$. Exposures at (a) $48 \mathrm{~min}$., (b) $96 \mathrm{~min}$., (c) $192 \mathrm{~min}$., (d) $256 \mathrm{~min}$. The menisci have been reinforced on the photographs for better reproduction. 
rapidly sedimenting component was found, the only boundary which appeared being that of the pigment.

\section{Molecular size of helicorubin and cytochrome $\mathrm{h}$}

The sedimentation coefficients of cytochrome $h$ and helicorubin which are given in Table 1 show that the results obtained with the Spinco ultracentrifuge are in very good agreement with the value obtained by $\operatorname{Dr}$ R. A. Kekwick and Dr E. Caspary, who kindly examined a preparation in the Svedberg oil-turbine ultracentrifuge. The rather low value of $10^{13} S_{20, w}=1.35$ found for helicorubin at pH 6.1 might be accounted for by the low ionic strength of the buffer used in this case $(I 0 \cdot 125)$.

The diffusion coefficient of cytochrome $h$ was determined in phosphate- $\mathrm{NaCl}$ buffer, $\mathrm{pH} 8, I$ 0.2. The value of $D_{20 \text {, w }}$ calculated by the method of moments was $8.4 \times 10^{-7} \mathrm{~cm}^{2} / \mathrm{sec}$. Taking the value of $1.73 \times 10^{-13}$ for $S_{20, w}$ and assuming the partial specific volume to be $\mathbf{0 . 7 3}$, then the molecular weight of the haemoprotein is $\mathbf{1 8 5 0 0}$. The frictional ratio $f / f_{0}$ calculated from these data is $1 \cdot 44$.

\section{Composition of purified preparations of cytochrome $\mathrm{h}$ and helicorubin}

Metals. Spectrographic analysis for metals, of samples of purified helicorubin and cytochrome $h$, kindly carried out by Dr R. L. Mitchell at Aberdeen, showed that only $\mathrm{Fe}$ was present in significant quantities. The other metals of biological interest such as $\mathrm{Cu}, \mathrm{Mn}, \mathrm{Mg}, \mathrm{Zn}$ and $\mathrm{V}$ were thus eliminated as possible additional prosthetic groups. The values obtained for $\mathrm{Fe}$ were in good agreement with those obtained by chemical analysis and spectroscopic estimations as haematin Fe.

Carbohydrate. It was found that in purified preparations which showed a single component both on ultracentrifuging at $\mathrm{pH} 6 \cdot 1$ and 8 and on electrophoresis in the Tiselius apparatus at $\mathrm{pH} 6.5,6.9$ and $\mathbf{7 \cdot 2}$, the measured dry weight of the salt-free pigment was always far in excess of the dry weight calculated from the haematin and protein content of the sample. This excess weight was due to

Table 1. Sedimentation coefficients of cytochrome $\mathrm{h}$ and helicorubin

$\begin{array}{rcc}\text { Preparation } & \mathrm{pH} & 10^{13} S_{20,} \\ \text { Cytochrome } h & 7.9 & 1 \cdot 73 \\ & 8 \cdot 0 & 1 \cdot 74^{*} \\ \text { Helicorubin } & 8 \cdot 0 & 1 \cdot 63 \\ & 8 \cdot 0 & 1 \cdot 68 \\ & 7.9 & 1 \cdot 56 \\ & 6 \cdot 1 & 1.35\end{array}$

* Value obtained by Dr R. A. Kekwick and Dr E. Caspary. Fig. 5 shows the electrophoresis schlieren pattern of this preparation. Ionic strength of phosphate buffers was between 0.2 and 0.29 , except in the last case, where it was $0 \cdot 125$. variable amounts of carbohydrate which accounted for $42-63 \%$ of the dry weight. The ratio of protein to haematin as shown by the $E_{\mathrm{p}} / E_{\mathrm{s}}$ ratio was, however, constant in all the purified preparations of cytochrome $h$ and helicorubin $(0 \cdot 285-0 \cdot 31)$. In the best preparations the $\mathrm{Fe} /$ protein quotient was about $0.3 \%$.

The molecular weight of cytochrome $h$ as calculated from the sedimentation and diffusion coefficients is 18500; this is in close agreement with the value obtained by assuming that the dry weight of the pure pigment is that of its protein content, plus the prosthetic group, and that the concentration of the solution in terms of haematin iron can be calculated from the height of the Soret band of the oxidized form of the pigment, a value of $E=1.475$ (for $1 \mathrm{~cm}$. light-path) corresponding to $1 \mu \mathrm{g}$. of $\mathrm{Fe} / \mathrm{ml}$.

On this basis cytochrome $h$ is a haemoprotein containing 1 atom of $\mathrm{Fe} / \mathrm{molecule}$ of $18500 \mathrm{~mol}$.wt. If, however, the molecular weight is calculated on the basis of the total dry weight, values varying from 32000 to 45000 are obtained. In order to investigate the relationship of the carbohydrate to the haemoprotein, attempts were made to separate the two substances by electrophoresis.

Moving-boundary electrophoresis in veronal buffer, pH 9.1, I 0.2, was carried out with cytochrome $h$ and helicorubin. In each case there were two main components: a smaller faster-moving component, the haemoprotein, and a larger slowermoving component which seemed to be colourless. The approximate areas under the two peaks were in the ratio $2: 3$.

In view of these results, which showed the separation from the haemoprotein of apparently uncoloured components, an attempt was made to remove the carbohydrate by electrophoretic fractionation on paper in $0.04 \mathrm{M}$ veronal buffer $(\mathrm{pH} \mathrm{9.0)}$ for about $30 \mathrm{hr}$. with a potential gradient of $5 \mathrm{v} / \mathrm{cm}$. The paper was then cut across into strips $2 \mathrm{~cm}$. wide; each strip was eluted separately for $4 \mathrm{hr}$. with water in the usual way, the volume of each eluate was measured and the total carbohydrate determined.

Since preliminary investigations of the carbohydrate had shown it to be a polysaccharide composed of several different sugars, it was not feasible to determine the absolute amount of carbohydrate by using as a standard a single sugar such as glucose. The amount of carbohydrate was therefore expressed as the optical density at $560 \mathrm{~m} \mu$. (due to the purple colour of the Molisch reaction) times dilution factor times volume of eluate with a cell of $1.0 \mathrm{~cm}$. light-path. The haematin content of each strip was estimated from the extinction of the Soret absorption band of the oxidized pigment, and for convenience was expressed in similar units. 
Although the haemoprotein migrates towards the positive electrode, in most experiments the red haemoprotein band was at the line of application to the paper or to the negative side of this line, owing to the general displacement of all components by the endosmotic flow, which is from positive to negative. The results of such experiments (Figs. 9 and 10) show that the maximum amount of carbohydrate is to be found to the negative side of the haemoprotein band where there is little if any haemoprotein. A very small amount of haemoprotein, differing slightly in the position of its absorption bands from the main red component and usually associated with some carbohydrate, gives rise to a small, faster-moving component under these conditions. In one experiment complete separation of carbohydrate and haemoprotein was obtained, all the carbohydrate being localized to the negative side of the haemoprotein.

These results show that the carbohydrate does not constitute part of the haemoprotein molecule and that electrophoresis in alkaline solution offers promise as a method for separating the haemoprotein from the polysaccharide associated with it. In no case did this procedure affect the properties of the haemoprotein or its protein/haematin ratio.

\section{Spectroscopic properties of helicorubin and cytochrome $\mathrm{h}$}

Once a helicorubin or cytochrome $h$ preparation has been treated with lead acetate, which removes most of the other pigments present in the starting material, the haemoprotein solution is clear orangered, with a parahaematin type of absorption spectrum; this consists of two very diffuse bands in the visible region of the spectrum, resembling those of oxidized cytochrome $c$.

When the haemoprotein is treated with a reducing agent such as sodium dithionite the colour of the solution changes to a rosy pink, and sharp absorption bands consisting of a strong $\alpha$-band and weaker $\beta$-band, as in a haemochromogen, are seen in the visible region. The absolute absorption spectra of helicorubin and cytochrome $h$ in the oxidized and reduced form calculated on a haematin-Fe basis are given in Figs. 11 and 12 and in Table 2, where it can be seen that these haemoproteins differ in certain respects : (1) The positions of the $\alpha-, \beta$ - and $\gamma$-(Soret) absorption bands of both oxidized and reduced helicorubin are nearer the red end of the spectrum than the corresponding bands of cytochrome $h$, the differences between the corresponding bands being $\alpha 5 \cdot 5, \beta 4$ and $\gamma 9 \mathrm{~m} \mu$. (2) The extinction coefficients of the $\alpha-, \beta$ - and $\gamma$-bands of reduced cytochrome $h$ are a little greater than those of the corresponding bands of helicorubin. (3) The shape of the 'protein' band between 290 and $250 \mathrm{~m} \mu$. differs in the two haemoproteins, that of cytochrome $h$

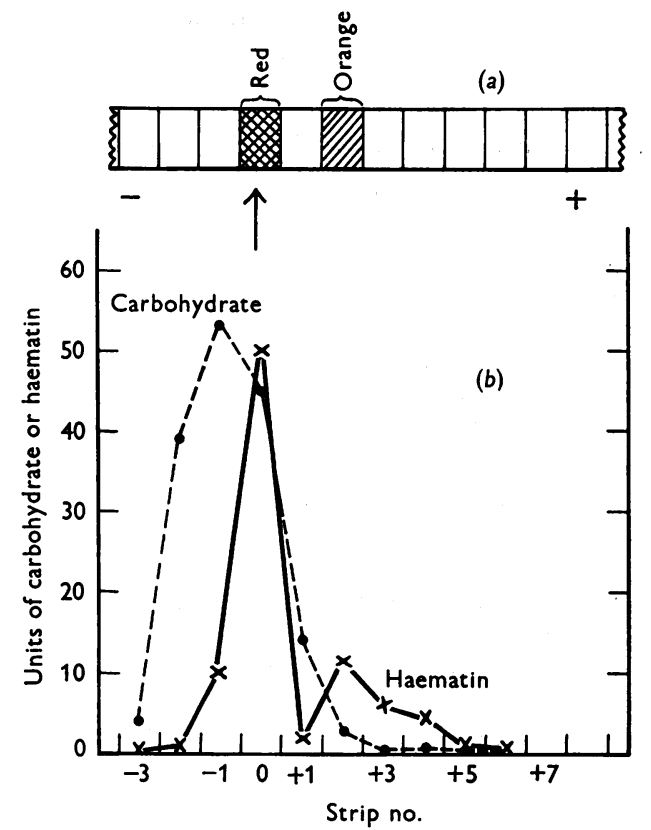

Fig. 9

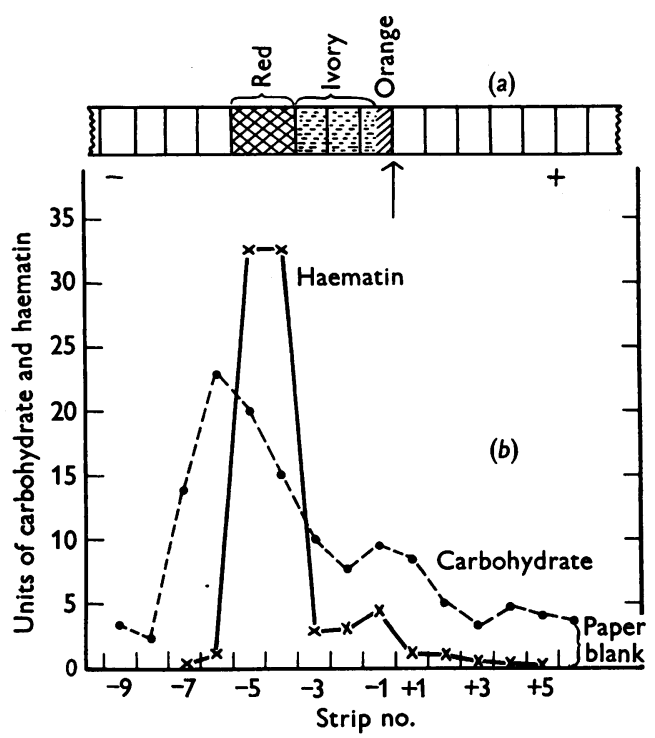

Fig. 10

Figs. 9 and 10. Separation of cytochrome $h$ and the polysaccharide accompanying it by electrophoresis on paper at $\mathrm{pH} 9$ in $0.04 \mathrm{M}$ veronal buffer. (a) Diagram of the distribution of the haemoprotein on the paper after $30 \mathrm{hr}$. electrophoresis. (b) Concentration of haemoprotein and polysaccharide contained in the eluate of each $2 \mathrm{~cm}$. wide strip. The methods of determining and defining the units are given in the text. The arrow marks the line of application of the pigment to the paper. 
showing a well-defined peak at $276 \mathrm{~m} \mu$. with one shoulder at $280 \mathrm{~m} \mu$. and another at $260 \mathrm{~m} \mu$. (Fig. 12).

These findings are constant for all purified preparations of helicorubin and cytochrome $h$. In the haemoprotein components separated from the main cytochrome $h$ component during electrophoretic fractionation on paper ( $P$ and $P^{\prime}$ in Fig. 1$)$ the Soret bands lie in intermediate positions between 410 and $415 \mathrm{~m} \mu$. (oxidized form), but never in the position characteristic of cytochrome $h$. In these fractions the $E_{\mathrm{p}} / E_{\mathrm{s}}$ ratio is much higher than in the main pigment fractions, as described above.

Effect of low temperatures on absorption spectra. It was mentioned above that the gastro-intestinal fluid when reduced in acid solution shows a double $\alpha$-band (Fig. 13c), but when reduction takes place in alkaline solution the $\alpha$-band appears sharper and is single when observed with the microspectroscope (Fig. 13a). The spectrophotometric curve of the acidreduced helicorubin does not, however, show two separate $\alpha$-bands but merely a shoulder at $563 \mathrm{~m} \mu$. in the slope of the main band lying at $558.5 \mathrm{~m} \mu$.

The effect of low temperature on the absorption spectra was observed with a microspectroscope as described by Keilin \& Hartree (1949). A dilute solution of the haemoprotein was mixed with an equal volume of glycerol and reduced with sodium dithionite, the concentration of pigment being such that the absorption bands were only just perceptible.

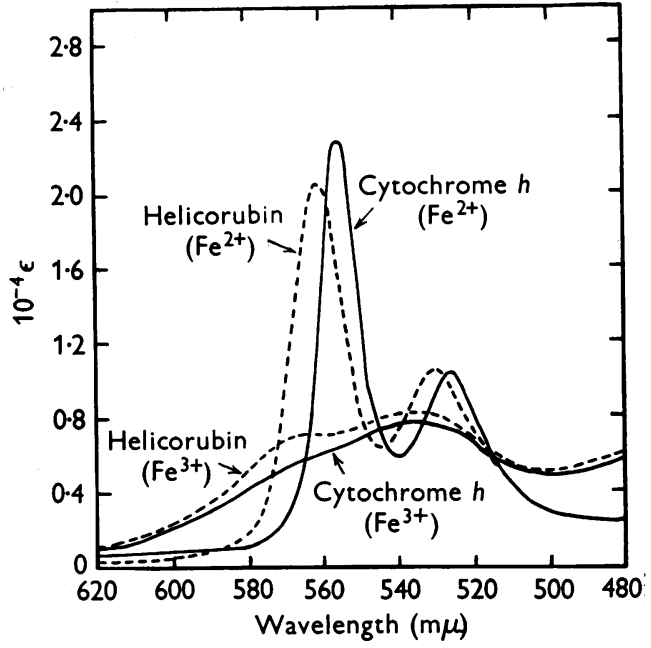

Fig. 11. Absorption spectra in the visible region of cytochrome $h$ and helicorubin in the oxidized and reduced forms (reduced with sodium dithionite). Cytochrome $h$ is in $0.03 \mathrm{M}$ phosphate buffer, $\mathrm{pH} \mathrm{7.3}$. Helicorubin is in $0.1 \mathrm{M}$ phosphate buffer, pH 7.6. The molecular extinction coefficient $\epsilon$ is calculated on the basis of the haematin Fe. This is determined by the extinction of the Soret band of cytochrome $h$, a value of $E_{408 \mathrm{~m} \mu .}=1.475$ (for $1 \mathrm{~cm}$. light-path) corresponding to $1 \mu \mathrm{g}$. of $\mathrm{Fe} / \mathrm{ml}$. These values were assumed to apply also in the case of helicorubin.

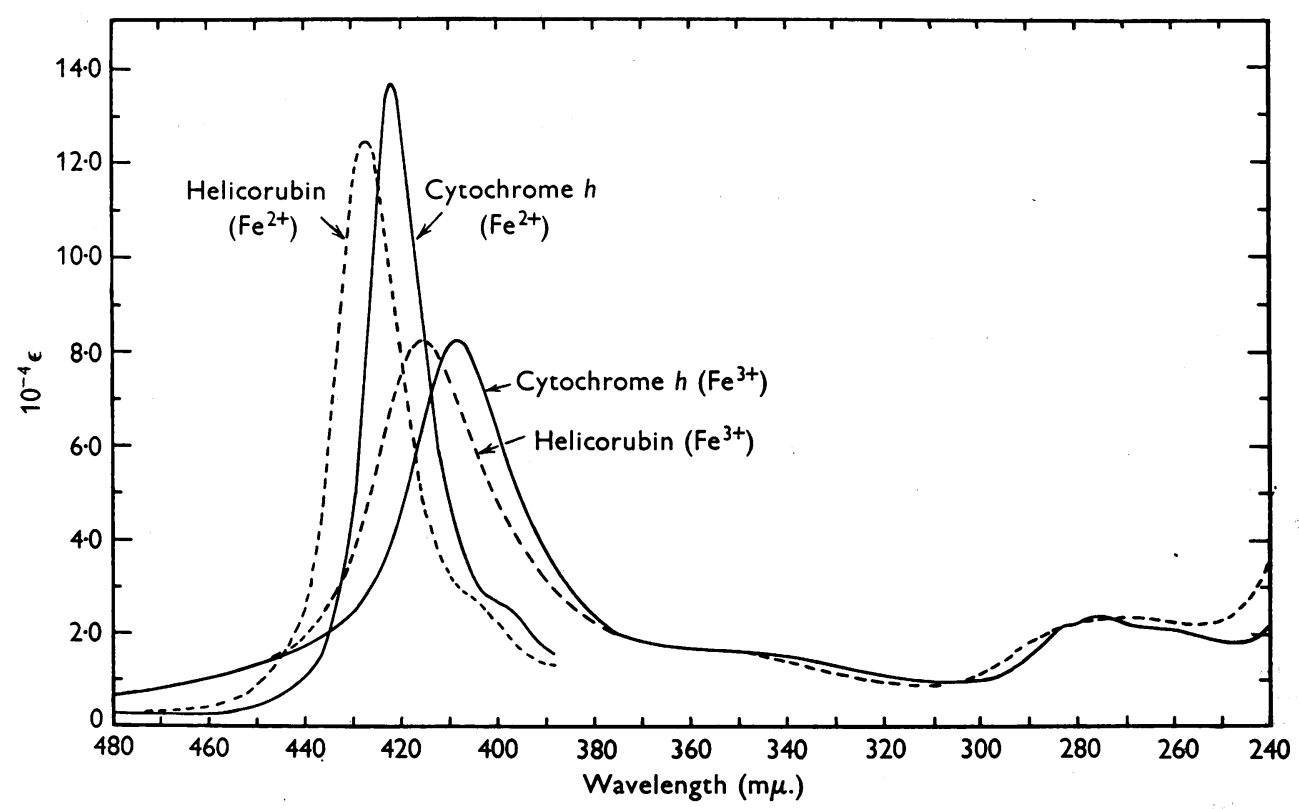

Fig. 12. Absorption spectra in the u.v. region of cytochrome $h$ and helicorubin in the oxidized and reduced forms (see Fig. 11). 
Table 2. Positions and molecular extinction coefficients of the absorption bands of helicorubin, cytochrome $\mathrm{h}$, cytochrome $\mathrm{c}$ and untreated gastro-intestinal fluid

\begin{tabular}{|c|c|c|c|c|c|c|c|c|}
\hline \multirow[b]{2}{*}{ Preparation } & \multirow[b]{2}{*}{ Form } & \multicolumn{2}{|c|}{$\alpha$-Band } & \multicolumn{2}{|c|}{$\beta$-Band } & \multicolumn{2}{|c|}{$\gamma$-Band } & \multirow[b]{2}{*}{$\epsilon_{276} / \epsilon_{\gamma}$} \\
\hline & & $\mathrm{m} \mu$. & $10^{-4} \epsilon$ & $\mathrm{m} \mu$. & $10^{-4} \epsilon$ & $\mathrm{m} \mu$. & $10^{-4} \epsilon$ & \\
\hline Cytochrome $c^{*}$ & $\begin{array}{l}\text { Oxidized } \\
\text { Reduced }\end{array}$ & $\begin{array}{l}566 \\
550\end{array}$ & $\begin{array}{l}1 \cdot 0 \\
2 \cdot 77\end{array}$ & $\begin{array}{l}529 \\
521\end{array}$ & $\begin{array}{l}1.2 \\
1.7\end{array}$ & $\begin{array}{l}407 \\
415\end{array}$ & $\begin{array}{l}10 \cdot 8 \\
13 \cdot 0\end{array}$ & $\frac{0.214}{-}$ \\
\hline Cytochrome $h$ & $\begin{array}{l}\text { Oxidized } \\
\text { Reduced }\end{array}$ & $\begin{array}{l}562 \dagger \\
556\end{array}$ & $\begin{array}{l}0 \cdot 60 \\
2 \cdot 27\end{array}$ & $\begin{array}{l}536 \\
526 \cdot 5\end{array}$ & $\begin{array}{l}0.77 \\
1.02\end{array}$ & $\begin{array}{l}408 \\
422\end{array}$ & $\begin{array}{r}8 \cdot 22 \\
13 \cdot 65\end{array}$ & $\stackrel{0.285}{-}$ \\
\hline Helicorubin & $\begin{array}{l}\text { Oxidized } \\
\text { Reduced }\end{array}$ & $\begin{array}{l}564 \dagger \\
561 \cdot 5 \ddagger\end{array}$ & $\begin{array}{l}0.72 \\
2 \cdot 05\end{array}$ & $\begin{array}{l}535 \\
530\end{array}$ & $\begin{array}{l}0.83 \\
1 \cdot 06\end{array}$ & $\begin{array}{l}415 \cdot 5 \\
427\end{array}$ & $\begin{array}{c}8 \cdot 2 \\
12 \cdot 45\end{array}$ & $\stackrel{0 \cdot 285}{-}$ \\
\hline Gastro-intestinal fluid (acid) & $\begin{array}{l}\text { Oxidized } \\
\text { Reduced }\end{array}$ & $\begin{array}{l}565 \dagger \\
558 \cdot 5 \ddagger \\
563 \dagger\end{array}$ & - & $\begin{array}{l}532 \dagger \\
527\end{array}$ & - & $\begin{array}{l}412 \\
426\end{array}$ & 二 & 二 \\
\hline
\end{tabular}

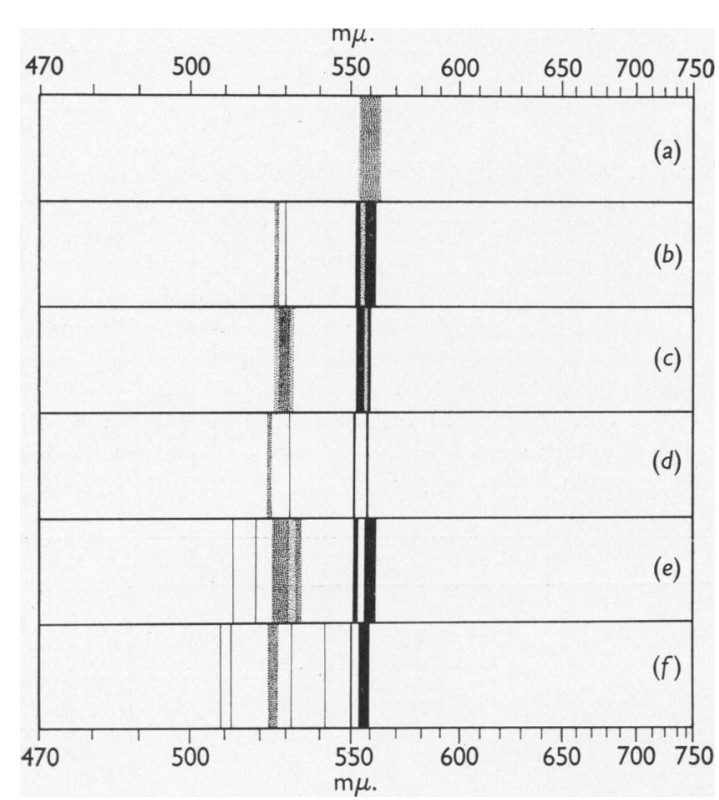

Fig. 13. Effect of low temperatures on the absorption spectra of helicorubin and cytochrome $h$ as seen with the microspectroscope. (a) Untreated helicorubin, $\mathrm{pH} 8.0$ at $20^{\circ}$. (b) The same after cooling to $-192^{\circ}$. (c) Untreated helicorubin, $\mathrm{pH} 4.4$ at $20^{\circ}$, showing 'acid doubling' of the $\alpha$-band. (d) The same (diluted) at $-192^{\circ}$. (e) Purified helicorubin, $-192^{\circ}$. ( $f$ ) Purified cytochrome $h,-192^{\circ}$. All solutions of haemoprotein mixed with an equal volume of glycerol were cooled in liquid air and re-cooled after devitrification was complete (see text).

The solution was then cooled in liquid air $\left(-192^{\circ}\right)$ and allowed to devitrify, and when the opacity due to crystallization had set in it was cooled once more to stabilize this condition. Three types of pigment were examined in this way in both acid and alkaline solutions: untreated gastro-intestinal fluid (crude helicorubin), purified helicorubin and purified cytochrome $h$.
The untreated alkaline crude helicorubin which at $20^{\circ}$ showed a diffuse $\alpha$-band centred at $560 \mathrm{~m} \mu$. (Fig. 13a) on cooling showed a double $\alpha$-band with a wider component at $560 \mathrm{~m} \mu$. and a very sharp narrow band at $552 \mathrm{~m} \mu$. with some shading between these bands. The $\beta$-band lay at $526 \mathrm{~m} \mu$. and a very faint additional band appeared at $530 \mathrm{~m} \mu$. (Fig. 13b).

In acid solution ( $\mathrm{pH} \mathrm{4.4)}$ the $\alpha$-band at room temperature showed the typical 'acid doubling', the two components of the band lying at about 563 and $558 \mathrm{~m} \mu$., with considerable shading between them; the $\beta$-band was at about $530 \mathrm{~m} \mu$. (Fig. 13c). On cooling, the $\alpha$-band appeared as two very sharp bands at 560 and $551 \mathrm{~m} \mu$., with no shading between them, and the $\beta$-band at about $525 \mathrm{~m} \mu$. was again accompanied by a faint band at $532 \mathrm{~m} \mu$. (Fig. 13d).

With purified helicorubin even more fine structure was revealed by cooling (Fig. 13e). At the temperature of liquid air the $\alpha$-band consists of two sharp bands separated by a clear space, the band at $560 \mathrm{~m} \mu$. being broader than that at $552 \mathrm{~m} \mu$. The $\beta$-band is now centred at about $526 \mathrm{~m} \mu$. and there are additional very faint narrow bands at 532, 519 and $512 \mathrm{~m} \mu$. This absorption spectrum is given by both acid and alkaline solutions.

It therefore seems likely that in reduced helicorubin the $\alpha$-band always consists of two component bands in both acid and alkaline solution, but that in alkaline solution these two bands are probably less than 3 or $4 \mathrm{~m} \mu$. apart and can be resolved into their component bands only at the temperature of liquid air.

With cytochrome $h$, the picture at low temperatures is somewhat different (Fig. 13f). There is great sharpening and intensification of the $\alpha$-band, which remains centred at about $556 \mathrm{~m} \mu$, and a very fine satellite band appears on its short-wavelength side at $550 \mathrm{~m} \mu$. In addition to the $\beta$-band at $524 \mathrm{~m} \mu$. very fine and faint bands appear at $542,532,512$ and $509 \mathrm{~m} \mu$. This absorption spectrum, which is the 
same in both acid and alkaline solutions, resembles that of cytochrome $c$ examined under the same conditions (Keilin \& Hartree, 1949).

\section{DISCUSSION}

In the course of the present investigation both the helicorubin from the gastro-intestinal fluid and cytochrome $h$ from the digestive gland were isolated and obtained in a pure state as haemoprotein compounds. The only impurity which remains in these preparations is a polysaccharide which does not appear to interfere with the study of either the physicochemical or the biological properties of these haemoproteins.

Cytochrome $h$ most likely represents the intracellular form of helicorubin found in the digestive gland, from which it may be secreted together with digestive enzymes and other products during the normal physiological activity of the gland much in the same way as peroxidase, xanthine oxidase and other biologically important products are secreted in milk by the cells of the mammary gland. During the secretory activity of the digestive gland the cytochrome $h$ is probably modified in some way to give rise to helicorubin. Although such a transformation of cytochrome $h$ has not so far been obtained in vitro, a change in the reverse direction was observed under certain conditions. Thus on prolonged paper electrophoresis at $\mathrm{pH} 4$ or after 1-2 days' dialysis at this $\mathrm{pH}$, helicorubin was found to acquire the electrophoretic and spectroscopic properties of cytochrome $h$; but whether it becomes identical with the latter in all respects has not yet been ascertained.

The most highly purified samples of cytochrome $h$ and helicorubin each had an $E_{\mathrm{p}} / E_{\mathrm{s}}$ ratio of 0.285 . These results were obtained from preparations where the $E_{\mathrm{p}} / E_{\mathrm{s}}$ ratio immediately before electrophoresis was $0 \cdot 44-0 \cdot 5$. Material which at this stage had an $E_{\mathrm{p}} / E_{\mathrm{s}}$ ratio of 1.0 never yielded any fractions with an $E_{\mathrm{p}} / E_{\mathrm{s}}$ ratio of less than about 0.34 . This shows that electrophoretic fractionation has certain limitations and is unable to remove from the haemoprotein other protein material which should have been removed in the pre-electrophoretic stages. Thus electrophoresis on paper cannot be used as a 'short cut' to bypass any of the previous steps in the isolation of the haemoprotein.

It was shown that the most highly purified preparations of both helicorubin and cytochrome $h$ contained about $50 \%$ of their dry weight as polysaccharide, yet these preparations showed a single component in the Spinco ultracentrifuge and on moving-boundary electrophoresis between pH 6 and 7 , although at $\mathrm{pH} 9$ the polysaccharide was revealed as a second component. The value of 18500 for the molecular weight of cytochrome $h$, calculated from the sedimentation and diffusion coefficients, agreed with that calculated from the protein content of the sample and from the concentration of the pigment determined spectrophotometrically, assuming one atom of haematin iron/ molecule of haemoprotein.

The problem which remains to be answered is why only a single boundary, that due to the haemoprotein, is observed on ultracentrifuging and what happens to the polysaccharide under these conditions. To answer this the following two tentative suggestions can be considered: (1) The polysaccharide may have a sedimentation coefficient of the same order as that of the haemoproteins, and judging from the shape of the single sedimentation boundary is unlikely to be a very asymmetrical molecule. (2) The polysaccharide may be so polydisperse as not to give any definite boundary.

The problem will be solved only when the haemoprotein is completely separated from the polysaccharide. In this respect paper electrophoresis in alkaline buffer, e.g. at $\mathrm{pH}$ 9, offers some promise, but it is possible that ultimately better methods may be found. It is, however, clear at this stage that the polysaccharide does not form part of the haemoprotein molecule.

The diffusion coefficient of helicorubin has not been determined, but as its sedimentation coefficient and other properties are very similar to those of cytochrome $h$, it is reasonable to assume that the molecular weight of helicorubin is also in the region of 18000 .

Although several cytochrome components have been isolated in a soluble form, it is appropriate that at this stage the physical properties of cytochrome $h$ and helicorubin should be compared only with those of cytochrome $c$, since this is the component of animal origin which has been most extensively studied (Table 3).

Like cytochrome $c$, both cytochrome $h$ and helicorubin are small molecules each containing one atom of iron/molecule. It will be remembered that early estimations of the molecular weight of cytochrome $c$ gave values of 15600 (Svedberg, 1937), and it was only after the haemoprotein had been more extensively purified that the lower value of 13000 was found (Pedersen, 1951). Recently the problem was reinvestigated by Ehrenberg \& Paléus (1955), who found a variation in the sedimentation coefficients of horse and ox cytochrome $c$ according to the method of preparation used; thus for horse cytochrome c containing $0.41 \%$ of $\mathrm{Fe}$,

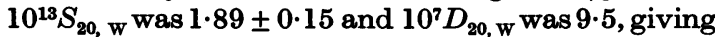
$f / f_{0}=1 \cdot 34$, whereas in preparations containing be. tween 0.31 and $0.36 \%$ of $\mathrm{Fe}, 10^{13} S_{20, \text { w }}$ varied between 1.61 and $1 \cdot 55$, giving values of $f / f_{0}$ of $1 \cdot 41-1 \cdot 43$. Since these sedimentation coefficients were obtained with a Spinco analytical ultracentrifuge 
Table 3. Comparison of the physical properties of helicorubin, cytochrome $\mathrm{h}$ and mammalian cytochrome $\mathrm{c}$

\begin{tabular}{|c|c|c|c|}
\hline Property & Cytochrome $c$ & Cytochrome $h$ & Helicorubin \\
\hline Colour, oxidized & Orange red & Orange red & Orange red \\
\hline Colour, reduced & Salmon pink & Rose pink & Rose pink \\
\hline \multicolumn{4}{|l|}{ Position of absorption bands ( $\mathrm{m} \mu$.) } \\
\hline Oxidized form: Soret & 407 & 408 & $415 \cdot 5$ \\
\hline Reduced form: $\alpha$ - and $\beta$ - & 550,521 & $556,526 \cdot 5$ & $561 \cdot 5,530$ \\
\hline Soret & 415 & 422 & 427 \\
\hline Atom of $\mathrm{Fe} / \mathrm{mol}$. & 1 & 1 & 1 \\
\hline $10^{13} S_{20, w}$ & $1 \cdot 83^{*}$ & $1 \cdot 73$ & $1 \cdot 62$ (av.) \\
\hline $10^{7} D_{20, w}^{20, w}$ & $11 \cdot 3^{*}$ & $8 \cdot 4$ & - \\
\hline Mol.wt. & $13000 *$ & 18500 & - \\
\hline$f / f_{0}$ & $1 \cdot 29 *$ & $1 \cdot 44$ & - \\
\hline Partial sp.vol. & $0 \cdot 707^{*}$ & 0.73 (assumed) & - \\
\hline Isoelectric point & $\mathrm{pH} 10.65 \dagger$ & $<\mathrm{pH} \mathrm{4.3}$ & $<\mathrm{pH} \mathrm{4.3}$ \\
\hline Thermostability 70 & Stable & Stable & Stable \\
\hline
\end{tabular}

the data given in Tables 1 and 3 for cytochrome $h$ and helicorubin may be more appropriately compared with these results than with those previously obtained for cytochrome $c$ by Pedersen. It may well be that, if the sedimentation and diffusion coefficients are redetermined for cytochrome $h$ which has been freed of carbohydrate and has been further purified, somewhat different values for the molecular weight may be obtained.

In the oxidized form, cytochrome $h$ and helicorubin are of the same colour as cytochrome $c$, but on reduction their colour is a rose pink whereas reduced cytochrome $c$ is salmon pink. Although the absorption spectra of reduced cytochrome $h$ and helicorubin (Figs. 11, 12 and Table 2) closely resemble that of cytochrome $c$ (Keilin \& Slater, 1953) they differ in several respects: (1) The $\alpha-, \beta$ and Soret absorption bands of reduced helicorubin and cytochrome $h$ are at longer wavelengths than the corresponding bands of reduced cytochrome $c$. (2) The extinction coefficients of the $\alpha$-and $\beta$-bands of cytochrome $h$ and helicorubin in both the oxididized and reduced forms and the Soret band of the oxidized form are lower than the corresponding bands of cytochrome c. (3) The $\delta$-band (in the oxidized form of the pigment), though present at about $350 \mathrm{~m} \mu$. in cytochrome $h$ and at about $360 \mathrm{~m} \mu$. in helicorubin, is not as well defined as that of cytochrome $c(346 \mathrm{~m} \mu$.). (4) The protein band of cytochrome $h$ always shows the presence of component bands at about 282,276 and $260 \mathrm{~m} \mu$., whereas both cytochrome $c$ and helicorubin show only a smooth curve with its maximum at $276 \mathrm{~m} \mu$.

The chief difference between the physical properties of helicorubin and cytochrome $h$ lies in the fact that all the absorption bands of helicorubin are nearer the red end of the spectrum than are the corresponding bands of cytochrome $h$. In addition, the $\alpha$-band of reduced helicorubin has, in slightly acid solution, two components at 563 and $558.5 \mathrm{~m} \mu$., whereas in alkaline solution only one, slightly asymmetric band is seen."
At the temperature of liquid air both crude and purified helicorubin in both acid and alkaline solutions show two separate components of the $\alpha$-band, but cytochrome $h$ under the same conditions shows a single $\alpha$-band with a 'satellite' band beside it as does cytochrome $c$. It was recently shown by Keilin \& Hartree (1955) that if the maxima of two absorption bands are $4 \mathrm{~m} \mu$. or less apart, they cannot be resolved spectrophotometrically, but that the two component bands can be clearly seen after they have become sharper at the temperature of liquid air. It therefore appears that in helicorubin the $\alpha$-band has two components, which are centred at $4 \mathrm{~m} \mu$. or more from each other in acid material but are situated closer to each other in alkaline solution. The significance of these two components and the changes in their positions relative to each other cannot yet be explained. Cytochrome $f$, another acidic type of cytochrome which is found in plants, shows a somewhat similar effect (Davenport $\&$ Hill, 1952). Here the $\alpha$-band of the reduced pigment lying at $555 \mathrm{~m} \mu$. becomes progressively more asymmetrical with a rise of $\mathrm{pH}$ (as seen with a microspectroscope) and at $\mathrm{pH} 10.8$ it is resolved into two components, a sharp band at $556 \mathrm{~m} \mu$. and a weaker band at $551 \mathrm{~m} \mu$.; these bands can then be resolved spectrophotometrically. In this case, too, no explanation can be offered.for the effect of $\mathrm{pH}$ on the spectrum.

So far it has been found that the cytochromes $c$ of different animals are basic proteins. The only acidic type of haemoprotein which has been described is cytochrome $f$ of plants, which has an isoelectric point of 4.7 (Davenport \& Hill, 1952). The isoelectric points of helicorubin and cytochrome $h$ have not been determined accurately, but in each case they were found to lie below pH $4 \cdot 3$, helicorubin being the more acidic of the two haemoproteins: In view of these findings it would be of great interest to determine and compare the amino acid composition of these proteins and the mode of linkage of the prosthetic group to the protein. 
Although helicorubin has been known for almost eighty years, it was generally considered in the textbooks and reviews merely as a biological curiosity; now that it has been shown to be closely related to cytochrome $h$, the study of the structure and biochemical properties of these two haemoproteins may prove to be of great help in similar studies of cytochrome components as well as of other haemoprotein compounds.

\section{SUMMARY}

1. Helicorubin is a natural haemochromogen found free in the gastro-intestinal tract of snails and some other invertebrates. Since its discovery by Sorby in 1876 the only studies that have been made of its properties were carried out on crude material or on very impure preparations

2. A method is described here for the purification of this haemoprotein from the gastro-intestinal fluid of the edible snail (Helix pomatia).

3. A very similar haemochromogen, present in the tissues of the gastric gland (hepatopancreas) of the snail, has also been isolated and obtained in a greatly purified state. In view of the intracellular localization of this haemochromogen and of some of its properties, it is described here under the name cytochrome $h$.

4. Preparations of helicorubin and cytochrome $h$ were obtained which gave single symmetrical boundaries of the haemoproteins in the ultracentrifuge and on electrophoresis in the Tiselius apparatus. Although these preparations still contain variable concentrations of a polysaccharide material, its presence is not revealed in these experiments.

5. Evidence that the polysaccharide does not form part of the haemoprotein molecules, and a possible method for the complete separation of the polysaccharide from the haemoproteins, are discussed.

6. The molecular weight of helicorubin and of cytochrome $h$, calculated from the sedimentation and diffusion constants as well as from the iron and protein contents of the preparations is about 18500.

7. Helicorubin and cytochrome $h$ are both acidic haemoproteins, their isoelectric points lying below pH 4.3; they can, however, be separated electrophoretically from a mixture, helicorubin being the more acidic of the two.

8. Helicorubin and cytochrome $h$ each contain one atom of iron/molecule.

9. Both 'haemoproteins are capable of undergoing oxidation and reduction: in the reduced and oxidized states the absorption spectra are of typical haemochromogen and parahaematin types respectively.
10. Their absorption bands, when compared with those of the cytochrome components, are seen to lie much nearer the position of those of cytochrome $b$ than of cytochrome $c$. The absorption bands " of helicorubin lie at longer wavelengths than the corresponding bands of cytochrome $h$.

11. Helicorubin and cytochrome $h$, like cytochrome $c$ but unlike other known components of cytochrome, are heat-stable haemoproteins.

12. Helicorubin and cytochrome $h$, unlike cytochrome $c$, do not combine with carbon monoxide at any $\mathrm{pH}$.

13. Helicorubin, which is always found free in solution in the gastro-intestinal fluid of snails, is intimately connected with the cytochrome $h$ present in the cells of the digestive gland, and probably represents a slightly modified form of cytochrome $h$ liberated with other substances during the normal secretory activity of this gland.

Helicorubin, which was hitherto considered merely as a biological curiosity, is in fact an extracellular form of a component of cytochrome which shares many of its properties with the typical components of the cytochrome system, including the ability to react with biological oxidation-reduction systems which will be dealt with in a later paper.

The greater part of this work was carried out while the author was holding a Beit Memorial Research Fellowship. I wish to thank Dr R. L. Mitchell for spectrographic examination of the haemoproteins for metals; Dr R. A. Kekwick and Dr E. Caspary for examining one of the preparations in the ultracentrifuge and for their valuable advice concerning the determination of the sedimentation and diffusion coefficients; Dr R. Markham for helpful suggestions in connexion with the calculation of the diffusion coefficient; and $\mathrm{Mr}$ M. W. Rees for confirming the protein-nitrogen estimations. Thanks are also due to $\mathrm{Mr}$ B. E. Boon for technical assistance with the ultracentrifuge runs and to Mr B. R. Slater for his valuable assistance with the diffusion measurements and for carrying out the electrophoretic runs in the Tiselius apparatus.

\section{REFERENCES}

Abelin, I. (1938). Biochem. Z. 297, 203.

Anson, M. L. \& Mirsky, A. E. (1925). J. Physiol. 40, 221.

Consden, R. \& Stanier, W. M. (1952). Nature, Lond., 170, 1069.

Davenport, H. E. \& Hill, R. (1952). Proc. Roy. Soc. B, 139, 327.

Devor, A. W. (1950). J. Amer. chem. Soc. 72, 2008.

Dhéré, C. (1919). J. Physiol. Path. gén. 18, 239.

Dhéré, C. \& Vegezzi, G. (1917a). J. Physiol. Path. gén. 17, 44.

Dhéré, C. \& Vegezzi, G. (1917b). J. Physiol. Path. gén. 17, 53.

Ehrenberg, A. \& Paléus, S. (1955). Acta chem. scand. 9, 538. Hartree, E. F. (1952). Biochem. J. 52, 619.

Hill, R. \& Keilin, D. (1933). Proc. Roy. Soc. B, 114, 104. Kahn, D. S. \& Polson, A. (1947). J. phys. Chem. 51, 816. 
Karrer, P., Schubert, P. \& Wehrli, W. (1925). Helv. chim. acta, 8, 797.

Keilin, D. \& Hartree, E. F. (1945). Biochem. J. 39, 289.

Keilin, D. \& Hartree, E. F. (1949). Nature, Lond., 164, 254.

Keilin, D. \& Hartree, E. F. (1955). Nature, Lond., 176, 200.

Keilin, D. \& Slater, E. C. (1953). Brit. med. Bull. 9, 89.

Krukenberg, C. F. W. (1882). Vergleichende Physiologische Studien, series 2, part 2, p. 63. Heidelberg.

MacMunn, C. A. (1883). Proc. Roy. Soc. 35, 370.

MacMunn, C. A. (1885). Phil. Trans. 176, 641.

MacMunn, C. A. (1886a). Phil. Trans. 177, 235.

MacMunn, C. A. (1886b). Phil. Trans. 177, 267.
Markham, R. (1942). Biochem. J. 36, 790.

Markham, R. \& Smith, J. D. (1951). Biochem. J. 49, 401.

Pedersen, K. O. (1951). Quoted by Paul, K. G. In The Enzymes, vol. 2, part I, p. 375. Ed. by Sumner, J. B. \& Myrbäck, K. New York: Academic Press, Inc.

Roche, J. \& Morena, J. (1936a). C.R. Soc. Biol., Paris, 123, 1215.

Roche, J. \& Morena, J. (1936b). C.R. Soc. Biol., Paris, 123, 1218.

Sorby, H. C. (1876). Quart. J. micr. Sci. 16, 76.

Svedberg, T. (1937). Chem. Rev. 20, 81.

Theorell, H. \& Åkesson, Å. (1941). J. Amer. chem. Soc. 63, 1804.

\title{
Toxic Liver Injury
}

\section{THE METABOLISM OF DIMETHYLNITROSAMINE}

\author{
By P. N. MAGEE \\ Toxicology Research Unit, Medical Research Council Laboratories, Woodmansterne Road, \\ Carshalton, Surrey
}

\section{(Received 29 May 1956)}

In a previous paper (Barnes \& Magee, 1954) dimethylnitrosamine was shown to cause acute centrilobular necrosis of the liver in the rat, mouse, guinea pig, rabbit and dog, when given in doses of the order of $25 \mathrm{mg}$. $/ \mathrm{kg}$. body weight. No gross abnormality was found in organs or tissues other than the liver. In long-term feeding experiments, when dimethylnitrosamine was added to the diet of rats at a level of 50 parts per million, a high incidence of malignant hepatic tumours occurred, with no evidence of primary tumours elsewhere. In similar experiments with rabbits no tumours were produced (Magee \& Barnes, 1956).

It appears that dimethylnitrosamine is a highly specific liver poison, and the present paper describes experiments which were performed in the hope of throwing some light on the mechanism of this specificity. A polarographic method for the estimation of dimethylnitrosamine in tissues and body fluids has been developed in this Laboratory (Heath \& Jarvis, 1955) and this method was used to study the distribution of the compound in the animal body after administration, and its excretion.

\section{METHODS}

The animals used were albino rats of the Porton strain, mice of the C. 57 Chester Beatty strain and commercially obtained albino mice, and cross-bred rabbits. The rats and mice were maintained on M.R.C. diet 41 (Bruce \& Parkes, 1949) and the rabbits on M.R.C. $\operatorname{diet} 18$ (Bruce, 1947). Dimethylnitrosamine, when given orally, was diluted with water and administered by a metal cannula attached to a syringe. For parenteral administration dilution was with $0.9 \% \mathrm{NaCl}$. Intravenous injection was by tail vein in rats and by ear vein in rabbits, both procedures being without anaesthesia, unless otherwise stated. The compound was estimated in tissues and body fluids by the polarographic method of Heath \& Jarvis (1955). In determinations of the total body content of dimethylnitrosamine in rats the animals were killed by intraperitoneal injection of $\mathrm{Na}$ pentobarbital (Veterinary Nembutal, Abbott) and immediately frozen by immersion in liquid $\mathrm{N}_{2}$. The rats were then transferred to a bucket and fragmented by percussion with a heavy brass ram-rod. The fragments were disintegrated further in $2.5 \%(w / v)$ sulphosalicylic acid by means of an Atomix blender (Measuring and Scientific Equipment Ltd., London, S.W. 1), and the resulting tissue suspension was made up to a known volume and centrifuged. Dimethylnitrosamine was estimated in a suitable portion of the supernatant fluid. A similar procedure was used for whole mice except that they were killed by cervical dislocation, and it was found possible to disintegrate them in the blender without preliminary freezing. In experiments on the excretion of dimethylnitrosamine, rats were placed in conventional metabolism cages constructed of metal coated with bakelite. Urine and faeces were collected separately by means of a glass separator. Total hepatectomy was performed on rats by $\operatorname{Dr} K$. K. Cheng, using a two-stage technique (Cheng, 1951). The second stage of the operation on the previously prepared animals was carried out under ether anaesthesia. Control animals of similar weight to that of the hepatectomized rats underwent a sham operation, in which the abdomen was opened and closed. Dimethylnitrosamine was injected intravenously into the hepatectomized and the sham-operated control rats at operation, while they were still under anaesthesia. Total nephrectomy on rats was performed by $\mathrm{Dr} J$. M. Barnes, and again control animals underwent a sham operation, both 